Research Journal of Medical Sciences 4 (2): 64-67, 2010

ISSN: $1815-9346$

(C) Medwell Journals, 2010

\title{
Fertility Preferences and Contraceptive Behaviours among Married Women in a Suburban Part of Bursa, Turkey
}

\author{
Hakan Ozdemir, Zuleyha Alper and Nazan Bilgel \\ Department of Family Medicine, Faculty of Medicine, Uludag University, \\ 16059 Bursa, Turkey
}

\begin{abstract}
The aim of this study was to evaluate the fertility and contraceptive preferences of married women, who were living in a suburban area of a metropolitan city. Two hundred seventy four randomly chosen women attending the primary health care unit in this suburban area were included into this cross-sectional descriptive study. Printed questionnaires were applied during face-to-face interviews. Analyses were made by using SPSS 11.5 for windows and chi square, binary logistic regression analysis and Mann-Whitney U tests were used for statistical significance. All of the participants reported that they were aware of family planning and they have knowledge about the different methods. Seventy percent of the women were using any family planning method whereas $30.0 \%$ were not using. The most preferred method was coitus interruptus. The desired number of children was found as two. The results were similar to those of the previous studies and it can be concluded that the study group was in a transition period from rural to urban in terms of fertility and family planning preferences.
\end{abstract}

Key words: Contraception, contraceptive methods, family planning, birth control, fertility, Turkey

\section{INTRODUCTION}

The main aims of family planning programs are: reduction of maternal, perinatal and neonatal mortality, decrease in the unwanted pregnancies and abortions, prevention of sexually transmitted diseases and meeting the needs of people regarding sexuality and reproduction. Increasing contraceptive use could improve maternal and child health, reduce population growth and ensure better provision of resources around the world (Schenker and Elchalal, 1994).

Turkey, with a population of over 70 million, has an overall fertility rate of 2.15 per women and this rate, which is just above the fertility replacement level (2.10), points out that fertility transition in Turkey is ongoing gradually but continuously (Turkey Demographic and Health Survey, 2008).

According to the Turkey Demographic and Health Survey (2008) $73.0 \%$ of married women are using a method of contraception. Forty-six percent of married women use a modern contraceptive, while $27.0 \%$ use a traditional method (Turkey Demographic and Health Survey, 2008). The most preferred traditional method is withdrawal and one in every 4 married women uses this method whereas, the most preferred modern contraceptive methods are intra uterine devices and oral contraceptives
(Turkey Demographic and Health Survey, 2008). The aim of this study was to gain insight into childbearing practices, fertility and contraceptive preferences in a suburban area of a metropolitan city, which is located in the western part of Turkey.

\section{MATERIALS AND METHODS}

The contraceptive and fertility behavior was analyzed in a population of married women between 15-49 ages, living in the Emek suburban area of Bursa city. Two hundred seventy four randomly chosen women attending the primary health care unit, which is located at this suburban area were included in the study. All of the participants were informed about the study and asked for their written consent for the voluntarily participation. This study was approved by the institutional review committee. Printed questionnaires were used for the collection of the data. The questions were styled and ordered to extract information about women's contraceptive preferences, knowledge and attitudes. Age, educational attainment and occupation of women and their husbands, income of the family, total number of pregnancies, live births, still births, abortions, living and death children, current use of contraceptive methods, sex of children, preferences regarding male child, number of

Corresponding Author: Nazan Bilgel, Department of Family Medicine, Faculty of Medicine, Uludag University, 16059 Bursa, Turkey 
desired children and opinions regarding having many children were asked. The questionnaire was applied during a face-to-face interview with the researchers and filled without any identification marks. Data were analyzed using SPSS 11.5 for windows. Chi square, binary logistic regression analysis and Mann-Whitney U-tests were used for statistical significance.

\section{RESULTS AND DISCUSSION}

The mean age of women was $29.83 \pm 7.70($ Mean \pm SD) and most of them $(92.3 \%)$ were housewives. Their educational attainment was as follows: $22.6 \%$ illiterate; $55.8 \%$ primary school; $9.1 \%$ secondary school and $12.4 \%$ high school or more. Husbands' educational attainment was clearly better than women with a distribution of: $5.1 \%$ illiterate; $66.8 \%$ primary school; $16.8 \%$ secondary school and $11.3 \%$ high school or more. Most of the husbands were labour workers (53.3\%), whereas $6.9 \%$ were unemployed. Twenty four percent eight point of the participants had no social security. Some fertility characteristics of the study group are shown in Table 1.

All of the participants reported that they were aware of family planning and they have knowledge about the different methods. When this study was conducted, $70.0 \%$ of the women were using any family planning

Table 1: Some fertility characteristics of the participants

\begin{tabular}{llll}
\hline Fertility characteristics & Mean & SD & SE \\
\hline Age at first pregnancy (years) & 19.65 & 3.45 & 0.20 \\
Total pregnancies & 2.77 & 1.84 & 0.11 \\
Still births & 0.27 & 0.64 & 0.03 \\
Living children & 2.23 & 1.47 & 0.08 \\
Death children & 0.20 & 0.54 & 0.03 \\
Living male children & 1.24 & 1.15 & 0.06 \\
Abortion & 0.17 & 0.50 & 0.03 \\
Children under 5 years of age & 0.69 & 0.64 & 0.04 \\
Desired number of children & 2.46 & 0.72 & 0.04 \\
Desired number of male children & 1.29 & 0.82 & 0.05 \\
\hline
\end{tabular}

Table 2: Distribution of women according to their contraceptive behavior

\begin{tabular}{lll}
\hline Family planning method & $\mathrm{N}$ & $\%$ \\
\hline Current users & & \\
Intra uterine device & 59 & 30.7 \\
Oral contraceptives & 13 & 6.8 \\
Condom & 31 & 16.2 \\
Coitus interruptus & 63 & 32.8 \\
Any other & 26 & 13.5 \\
Total & 192 & 100.0 \\
\hline Reason for not using & $\mathrm{N}$ & $\%$ \\
Not users & & \\
Has no children & 10 & 12.2 \\
Wants more children & 12 & 14.6 \\
Pregnant & 11 & 13.4 \\
Gave birth shortly & 17 & 20.8 \\
Separate from husband & 6 & 7.3 \\
Menopause & 9 & 10.9 \\
Other & 17 & 20.8 \\
Total & 82 & 100.0 \\
\hline
\end{tabular}

method, whereas $30.0 \%$ were not using. Distribution of women according to the currently used family planning methods and reasons of non-usage is shown in Table 2 .

Logistic regression analysis showed no significant relationships between the current use of family planning and socio-demographic variables such as educational attainment of women and their husband's income of the family and occupation.

Table 3 shows the fertility characteristics of women, who were family planning users and non-users. Mean number of total pregnancies, living children, living male children and children under five years of age were significantly higher among current family planning users than non-users.

The opinion of participants regarding the advantages of having many children is shown in Table 4. Most of them $(85.4 \%)$ said that having more children has no advantages. Among currently family planning users this percentage was $88.5 \%$, whereas among non-users $78.0 \%$. The difference between users and non-users found to be statistically significant. The disadvantages of having more children were pointed out by the study group as follows: difficulties in caring (63.2\%); financial difficulties (23.1\%); harmful to mother's health (5.1\%) and other $(8.6 \%)$.

More than half of the women $(59.9 \%)$ said that if they unwillingly get pregnant they would prefer to give a birth rather than to have an abortion. Some $21.5 \%$ would prefer to have an abortion and $18.6 \%$ are not sure what they would do. Distribution of women regarding their answers to the question: What would you do if you get pregnant unwillingly? is shown in Table 5. In case of

Table 3: Fertility characteristics of family planning users and non-users

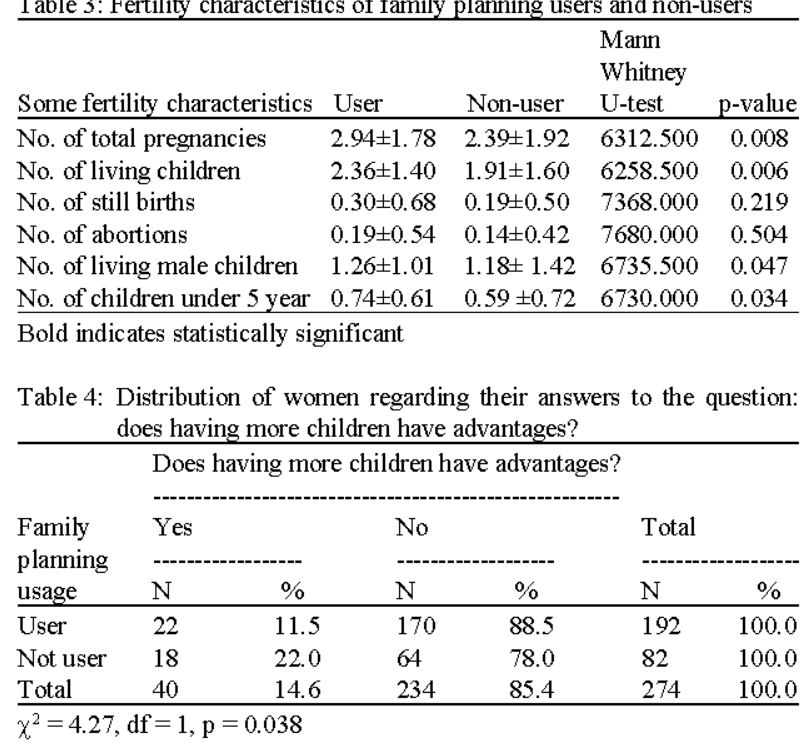


Res. J. Med.Sci., 4 (2): 64-67, 2010

Table 5: Distribution of women regarding their answers to the question: what would you do if you get pregnant again? What would you do if you get pregnant again?

\begin{tabular}{|c|c|c|c|c|c|c|c|c|}
\hline \multirow[b]{2}{*}{ Family planning } & \multicolumn{2}{|c|}{ Give birth } & \multicolumn{2}{|c|}{ Have an abortion } & \multicolumn{2}{|c|}{ Not sure } & \multicolumn{2}{|c|}{ Total } \\
\hline & $\mathrm{N}$ & $\%$ & $\mathrm{~N}$ & $\%$ & $\mathrm{~N}$ & $\%$ & $\mathrm{~N}$ & $\%$ \\
\hline User & 108 & 56.3 & 50 & 26.0 & 34 & 17.7 & 192 & 100.0 \\
\hline Not user & 56 & 68.3 & 9 & 11.0 & 17 & 20.7 & 82 & 100.0 \\
\hline Total & 164 & 59.8 & 59 & 21.5 & 51 & 18.6 & 274 & 100.0 \\
\hline
\end{tabular}

unwanted pregnancies, current family planning users wanted to have an abortion more than those who were not users. The factors affecting contraceptive and fertility behaviors of women in childbearing ages (15-49) in a suburban area of a metropolitan city in Turkey were investigated in this study. The analyses showed that nearly all of the women had knowledge about at least one contraceptive method and were aware of family planning. This finding was similar to those of Turkey Demographic and Health Survey (2008) and some other studies (Dinc et al., 2007; Vural et al., 1999; Yoldascan and Cetik, 2008). In Turkey, the total fertility rate is 2.15 and that means at the end of their childbearing period every women will have 2.15 children on average if the current fertility trends will continue (Turkey Demographic and Health Survey, 2008). In this study, the mean number of live births was found as 2.43 . This number is close to the total fertility rate of urban areas of Turkey, which was found as 2.67 on Turkey Demographic and Health Survey (2008). Another studies from Turkey, which took place in suburban areas found the mean number of live births as 2.0 and 2.4, respectively (Dinc et al., 2007; Topsever et al., 2006).

In this study, one among every 6 women have had an abortion. A previous study from a big city of Turkey found than one among every 3 women had undergone at least one abortion (Maral et al., 2007). It can be said that abortion is not preferred among the study group.

In this study, $70.0 \%$ of women were using any contraceptive method during the time of the survey and $30.0 \%$ not. Thirty seven point six percent of women used a modern contraceptive, while $32.4 \%$ used a traditional method at the time of survey. The most preferred method was coitus interruptus. Others were intrauterine device, condom and oral contraceptive, respectively. These results are similar to those of Turkey Demographic and Health Survey (2008). Another study from an urban settlement showed that $77.2 \%$ of women were using a family planning method but $24.0 \%$ were still using traditional methods and the most popular methods were coitus interruptus and intrauterine devices (Yoldascan and Cetik, 2008). Other Turkish studies revealed similar results (Dinc et al., 2007; Topsever et al., 2006; Vural et al., 1999).
This study showed no significant relationship between family planning usage and educational attainment of women, whereas many of the previous studies showed a rise in using family planning and modern methods with higher educational attainment (Cindoglu et al., 2008; Dinc et al., 2007; Yoldascan and Cetik, 2008; Topsever et al., 2006; Turkey Demographic and Health Survey, 2008; Vural et al., 1999). Another study discuss the determinants of the use of coitus interruptus in Turkey and concluded that empowerment of women in terms of better socio-economic status, better education, modern and liberal attitudes towards women and family planning seem to reduce coitus interruptus as the main method of contraception (Koc, 2000).

The desired number of children among the study group was two children and this result is similar to those of the previous studies (Cindoglu et al., 2008; Dinc et al., 2007; Yoldascan and Cetik, 2008; Topsever et al., 2006; Turkey Demographic and Health Survey, 2008; Vural et al., 1999). On the other side $60.0 \%$ of women concluded that they would give birth if they get pregnant unwillingly. Despite the legalization of induced abortions it is clear that most of the women did not prefer having an abortion.

\section{CONCLUSION}

In this study, it can be said that women in this study group were in a transition period from rural to urban fertility characteristics. They were motivated for using family planning but still the most popular methods they have used were the traditional methods.

\section{REFERENCES}

Cindoglu, D., I. Sirkeci and R.F. Sirkeci, 2008. Determinants of choosing withdrawal over modern contraceptive methods in Turkey. Eur. J. Contracept Reprod. Health Care, 13: 412-421.

Dinc, G., E. Eser, U.A. Cihan, S. Ay, T. Pala, G. Ergür and C. Ozcan, 2007. Fertility preferences, contraceptive behaviors and unmet needs: A gap between urban and suburban parts of a city. Eur. J. Contracept Reprod. Health Care, 12: 86-94. 
Koc, I., 2000. Determinants of contraceptive use and method choice in Turkey. J. Biosoc. Sci., 32: 329-342.

Maral, I., E. Durukan, S. Albayrak, N. Oztimur, A. Biri and M.A. Bumin, 2007. Induced abortion frequency in Ankara, Turkey, before and after the legal regulation of induced abortion. Eur. J. Contracept Reprod. Health Care, 12: $279-288$.

Schenker, J.G. and U. Elchalal, 1994. Behavioural and social issues in contraception. Curr. Opin. Obstet. Gynecol., 6: 543-546.
Topsever, P, M. Filiz, N. Aladag, R. Topalli, O. Cigerli and S. Gorpelioglu, 2006. Counselling and knowledge about contraceptive mode of action among married women: A cross-sectional study. BMC Womens Health, 6: 12-18.

Turkey Demographic and Health Survey, 2008. Preliminary report. Hacettepe University Institute of Population Studies, Ankara, pp: 9-20.

Vural, B., F. Vural, J. Diker and I. Yucesoy, 1999. Factors affecting contraceptive use and behavior in Kocaeli Turkey. Adv. Contracept., 15: 325-336.

Yoldascan, E. and M.O. Cetik, 2008. Family planning in rural Adana, Turkey. J. Biosoc. Sci., 400: 149-151. 